\title{
A High Sensitive LC-MS/MS Method for the Simultaneous Determination of Potential Genotoxic Impurities Carboxy Phenyl Boronic Acid and Methyl Phenyl Boronic Acid in Lumacaftor
}

\author{
Kartheek Srinivas Chidella1, Vijaya Bharathi Dasari², A. Jayashree1 \\ ${ }^{1}$ Center for Chemical Sciences and Technology, Institute of Science and Technology, \\ Jawaharlal Nehru Technological University Hyderabad, Hyderabad, Telangana \\ ${ }^{2}$ Aurobindo Pharma Laboratory Research Center II, Hyderabad, Telangana \\ Email: kartheeksrinivas2008@gmail.com
}

How to cite this paper: Chidella, K., Dasari, V.B. and Jayashree, A. (2021) A High Sensitive LC-MS/MS Method for the Simultaneous Determination of Potential Genotoxic Impurities Carboxy Phenyl Boronic Acid and Methyl Phenyl Boronic Acid in Lumacaftor. American Journal of Analytical Chemistry, 12, 74-86.

https://doi.org/10.4236/ajac.2021.123006

Received: March 7, 2021

Accepted: March 22, 2021

Published: March 25, 2021

Copyright $\odot 2021$ by author(s) and Scientific Research Publishing Inc. This work is licensed under the Creative Commons Attribution International License (CC BY 4.0).

http://creativecommons.org/licenses/by/4.0/ (c) (i) Open Access

\begin{abstract}
A simple, rapid, and highly sensitive LC-MS/MS method has been developed for the simultaneous and trace level quantification of underivatized boronic acids in lumacaftor active pharmaceutical ingredient. Chromatographic separation of boronic acids and lumacaftor achieved using Agilent Poroshell HPH C18 $150 \times 4.6 \mathrm{~mm} 2.7 \mu$ column with $0.1 \%$ ammonia in water as mobile phase $\mathrm{A}$ and $100 \%$ acetonitrile as mobile phase $\mathrm{B}$ at a flow rate of 0.25 $\mathrm{ml} / \mathrm{min}$. Gradient elution was used with a total method run time of $14 \mathrm{mi}$ nutes. Boronic acids were successfully ionized and quantified without derivatization using electrospray ionization in negative mode using tandem quadrupole mass spectrometry in multiple reactions monitoring mode. Method validation was performed as per ICH guidelines with good linearity over the concentration range of $0.05 \mathrm{ppm}$ to $5 \mathrm{ppm}$ of Lumacaftor test concentration for both the boronic acids with a correlation coefficient of $>0.99$. Recoveries were found good at different concentration levels and within the range of $80 \%-120 \%$. The developed method can be successfully used for the routine quantification of boronic acids at a concentration level of $20 \mathrm{ng} / \mathrm{ml}(1 \mathrm{ppm}$ with respect to $20 \mathrm{mg} / \mathrm{ml}$ lumacaftor).
\end{abstract}

\section{Keywords}

Boronic Acid, Genotoxic, LC-MS/MS, Lumacaftor 


\section{Introduction}

Boronic acids are used as chemical building blocks during the synthesis of organic compounds and are the most common intermediates used in the preparation of biaryl derivatives using Suzuki-Miyaura coupling [1] [2] [3]. Studies have been conducted to evaluate the mutagenic toxicity of commercially available boronic acids resulted in positive Ames test [3]. Boron containing compounds are potential mutagenic impurities and often controlled in drug substances as per International council of Harmonization (ICH) M7 [4] guidelines using highly sensitive analytical techniques like LC-MS/MS for quantification.

Lumacaftor is a pharmaceutical drug used in combination with Ivacaftor sold under the name of ORKAMBI approved by FDA for the treatment of genetic disease cystic fibrosis (CF) [5]. Cystic fibrosis results due to the defects in the cystic fibrosis transmembrane conductance regulator (CFTR) causes dysregulation of epithelial fluid transport in the lungs, gastrointestinal tract, and sweat glands and can cause progressive multi organ failure [6] [7] [8].

The aim of the current research work is to quantify mutagenic boronic acid impurities in Lumacaftor drug substance. During literature search we could find methods published for determination of boronic acids using SIM ionization mode in single quadrupole LCMS [9] [10], however in the present article we have analyzed boronic acids which using highly sensitive and selective triple quadrupole LC-MS/MS in Multiple reaction monitoring (MRM) mode. We could also find article published for derivatized boronic acids using LC-MS/MS [11] however we could analyze underivatized boronic acids in the present work using highly sensitive LC-MS/MS which can reduce the sample preparation time and efforts of derivatization and increase the throughput during analysis of multiple samples of lumacaftor drug substance. Several LCMSMS methods have published for the determination of Lumacaftor in combination with Ivacaftor in biological fluids [12] [13]. Chromatographic methods published for the determination of Lumacaftor in its bulk dosage form [14] [15]. As per the extensive literature survey performed, there is no data published for the quantification of boronic acids in lumacaftor using LC-MS/MS till date.

Both the possible boronic acids were procured based on the results obtained from computational structure analysis for mutagenicity alerts. The concentrations of boronic acid impurities in lumacaftor must be controlled at concentrations lower than $1 \mathrm{ppm}$ considering the maximum allowable dosage. In this paper, we present the LC-MS/MS method development for the simultaneous determination of carboxy phenyl boronic acid and methyl phenyl boronic acid in lumacaftor. The chemical structures of Carboxy phenyl boronic acid, Methyl phenyl boronic acid and Lumacaftor along with molecular formula and mono isotopic mass considering the most abundant isotope of boron are captured in Figure 1. The validation of the method in terms of limit of detection, limit of quantification, repeatability, accuracy, robustness, linearity and specificity is in accordance with ICH guidelines [16]. 
<smiles>O=C(O)c1ccc(B(O)O)cc1</smiles>

(a)<smiles>Cc1ccc(B(O)O)cc1</smiles>

(b)<smiles>Cc1ccc(NC(=O)C2(c3ccc4c(c3)OC(F)(F)O4)CC2)nc1-c1cccc(C(=O)O)c1</smiles>

(c)

Figure 1. Chemical structures of Carboxy phenyl boronic acid (a); Methyl phenyl boronic acid (b), Lumacaftor (c) compounds. (a) Molecular Formula: $\mathrm{C}_{7} \mathrm{H}_{7} \mathrm{BO}_{4}$, Monoisotopic Mass: $166.04374 \mathrm{Da}$; (b) Molecular Formula: $\mathrm{C}_{24} \mathrm{H}_{18} \mathrm{~F}_{2} \mathrm{~N}_{2} \mathrm{O}_{5}$, Monoisotopic Mass: 452.118378 Da; (c) Molecular Formula: $\mathrm{C}_{7} \mathrm{H}_{9} \mathrm{BO}_{2}$, Monoisotopic Mass: $136.069561 \mathrm{Da}$.

\section{Experimental}

\subsection{Reagents and Chemicals}

LCMS grade with highest purity of $>99.8 \%$ solvents and reagents were used. Water, Acetonitrile and Methanol were procured from Honeywell (Charlotte, NC, USA). Ammonium hydroxide solution was purchased from Fluka. Lumacaftor drug substance and boronic acids were procured from PS3 labs LLP, Hyderabad, India.

\subsection{Mobile Phase Preparation}

Mobile phase A was prepared by adding $1 \mathrm{ml}$ of ammonium hydroxide solution in $1000 \mathrm{ml}$ of water and mobile phase B was 100\% acetonitrile. Both the mobile phases were sonicated to degas and stored at ambient temperature for further usage. Mobile phases prepared freshly before each set of analysis.

\subsection{Preparation of Sample and Standard Solutions}

Weighed accurately $10 \mathrm{mg}$ each of carboxy phenyl boronic acid and Methyl phenyl boronic acid and transferred in $10 \mathrm{ml}$ volumetric flasks and made up to mark with $100 \%$ acetonitrile to obtain final concentration of $1000 \mu \mathrm{g} / \mathrm{ml}$. A 10 $\mu \mathrm{g} / \mathrm{ml}$ mixture of boronic acids were further prepared by addition of appropriate stock volumes and diluted with $80 \%$ Acetonitrile solution. Performed further dilution to $1 \mu \mathrm{g} / \mathrm{ml}$ mixture. Calibration standards were prepared from $1 \mu \mathrm{g} / \mathrm{ml}$ to achieve the final concentrations of $100,80,60,40,10,5$ and $1 \mathrm{ng} / \mathrm{ml}$.

Recovery experiment required spiking solutions which were prepared by weighing accurately $100 \mathrm{mg}$ of lumacaftor drug substance in $5 \mathrm{ml}$ volumetric flask and then add appropriate volume of boronic acids impurity mix stock to 
obtain a concentration of $20 \mathrm{ng} / \mathrm{ml}(1.0 \mathrm{ppm})$ and $5 \mathrm{ng} / \mathrm{ml}(0.25 \mathrm{ppm})$ with respect to test concentration of $20 \mathrm{mg} / \mathrm{ml}$ of lumacaftor. To ensure repeatability experiment performed in triplicates.

\subsection{LC-MS/MS Operating Conditions}

Chromatographic separation and detection performed using 1290 Infinity II UHPLC (Agilent technologies., Santa Clara, CA) equipped with stack of modules including binary pump, multisampler and diode array detector connected with an Agilent 6470 (Agilent technologies., Santa Clara, CA) LCMSMS triple quadrupole with Agilent Jet Stream (AJS) Electrospray Ionization interface. Poroshell HPH C18 $150 \times 4.6 \mathrm{~mm} 2.7 \mu$ column (Agilent technologies., Santa Clara, CA) was used to separate boronic acid impurities and lumacaftor using $0.1 \%$ ammonium hydroxide in water as Mobile phase A and $100 \%$ acetonitrile as mobile phase $B$ using gradient mode of elution at a flow rate of $0.25 \mathrm{ml} / \mathrm{min}$ with a run time of 14 minutes. The column oven temperature maintained at $40^{\circ} \mathrm{C}$ and the autosampler temperature maintained at $10^{\circ} \mathrm{C}$ with an injection volume of 20 $\mu \mathrm{l}$. The gradient program used as follows (time in $\mathrm{min} / \% \mathrm{~B}$ ): $0.00 / 15,2.00 / 15$, 6.00/90, 11.00/90, 11.1.00/15, 14/15.

Mass spectrometric conditions were optimized in ESI negative mode using MRM mode of acquisition for both the boronic acid impurities in the form of deprotonated molecular ions $(\mathrm{M}-\mathrm{H})^{-}$at $\mathrm{m} / \mathrm{z} 164.9$ and 135.1 respectively for carboxy phenyl boronic acid and methyl phenyl boronic acid impurities considering the most abundant isotope of Boron. Ionization source was operated with a capillary voltage $4500 \mathrm{~V}$, Nozzle voltage $2000 \mathrm{~V}$, Drying gas temperature $300^{\circ} \mathrm{C}$, Drying gas flow $12 \mathrm{l} / \mathrm{min}$, Nebulizer pressure $35 \mathrm{psi}$, Sheath gas temperature $350^{\circ} \mathrm{C}$, Sheath gas flow $10 \mathrm{l} / \mathrm{min}$ respectively. All parameters of LC and MS were controlled using Agilent Mass Hunter software 10.1 version.

\subsection{Method Validation}

Successful validation of the developed method in terms of Specificity, reproducibility, linearity, LOD, LOQ, robustness and solution stability executed, and the validation parameters conducted using ICH guidelines [16]. Initially to verify the sensitivity of the method, individual solutions of the impurities injected at absolute concentrations of $5.0 \mathrm{ng} / \mathrm{ml}(0.25 \mathrm{ppm}$ wrt lumacaftor $20 \mathrm{mg} / \mathrm{ml}$ test concentration) and obtained the $\mathrm{S} / \mathrm{N}$ ratio values. Further method reproducibility was established at $20 \mathrm{ng} / \mathrm{ml}(1.0 \mathrm{ppm}$ wrt lumacaftor $20 \mathrm{mg} / \mathrm{ml}$ test concentration) by injecting six replicates from the same vial. Next, the method linearity was evaluated from $1 \mathrm{ng} / \mathrm{ml}$ to $100 \mathrm{ng} / \mathrm{ml}(0.05-5.0 \mathrm{ppm})$ using seven different concentration levels. Calculation of slope, intercept and regression coefficient values employed using least square linear regression. Recovery experiment was executed in triplicate sets at two different concentration levels of $20 \mathrm{ng} / \mathrm{ml}(1.0$ ppm wrt test) and LOQ (0.25 ppm wrt test) to establish the efficiency. Assessment of specificity of the developed method in presence of lumacaftor drug sub- 
stance performed. Method robustness was tested by altering the mobile phase composition, flow rate and column temperature conditions. Solution stability also established at different time intervals to evaluate the stability criteria of the impurities.

\section{Results and Discussion}

\subsection{Chromatographic Method Development}

This study was conducted to develop highly sensitive and selective analytical method that could separate and quantify both the mutagenic boronic acid impurities in Lumacaftor drug substance.

For optimal peak shapes and good separation between lumacaftor and boronic acid impurities, initially started with $5 \mathrm{mM}$ ammonium formate buffer and adjusting several mobile phase $\mathrm{pH}$ and gradient conditions were evaluated but methyl phenyl boronic acid and lumacaftor getting coeluted and when altering $\mathrm{pH}$ conditions using $0.1 \%$ ammonium hydroxide solution provided the better peak shapes and sensitivities finally with Poroshell HPH $150 \times 4.6 \mathrm{~mm} 2.7 \mu$ column after parallelly checking different column options. Both the methanol and acetonitrile were evaluated for mobile phase B and concluded with acetonitrile due to better separation efficiency. Various flow rates were checked and finally concluded with $0.25 \mathrm{ml} / \mathrm{min} .40^{\circ} \mathrm{C}$ column temperature also helped in achieving the separation. The retention times of boronic acid impurities carboxy phenyl boronic acid and methyl phenyl boronic acid were observed to be 4.026 and $10.726 \mathrm{~min}$ respectively and lumacaftor eluted at $9.846 \mathrm{~min}$. Representative chromatograms for standard and spike samples with boronic acid impurities provided in Figure $2 \&$ Figure 3. Lumacaftor diverted to waste using time programmed events in method during the sample analysis using inbuilt divertor valve of MS to avoid the contamination during routine analysis.

\subsection{Optimization of MSMS Parameters}

Mass spectrometric conditions optimization aimed at developing simple, selective, highly sensitive and robust method for the determination of determination of underivatized boronic acids in lumacaftor drug substance. $1.0 \mu \mathrm{g} / \mathrm{ml}$ impurity mix solution was used to carry out MSMS method development. During initial stages of development negative mode ionization was found to be more sensitive due to the nature of the impurities, limiting the method development to negative ionization only. Critical compound dependent parameters like capillary, Nozzle and fragmentor voltages $(\mathrm{V})$ were optimized for boronic acids to obtain the desired response for parent molecular ions considering the most abundant isotope of Boron which are presented in Table 1. Further collision energies were optimized by checking with different Collison cell voltages to establish sensitive and reproducible MRM transitions for both the boronic acids. The MS/MS spectra for both the boronic acids at different collision energies were captured in Figure 4 , Figure 5. 


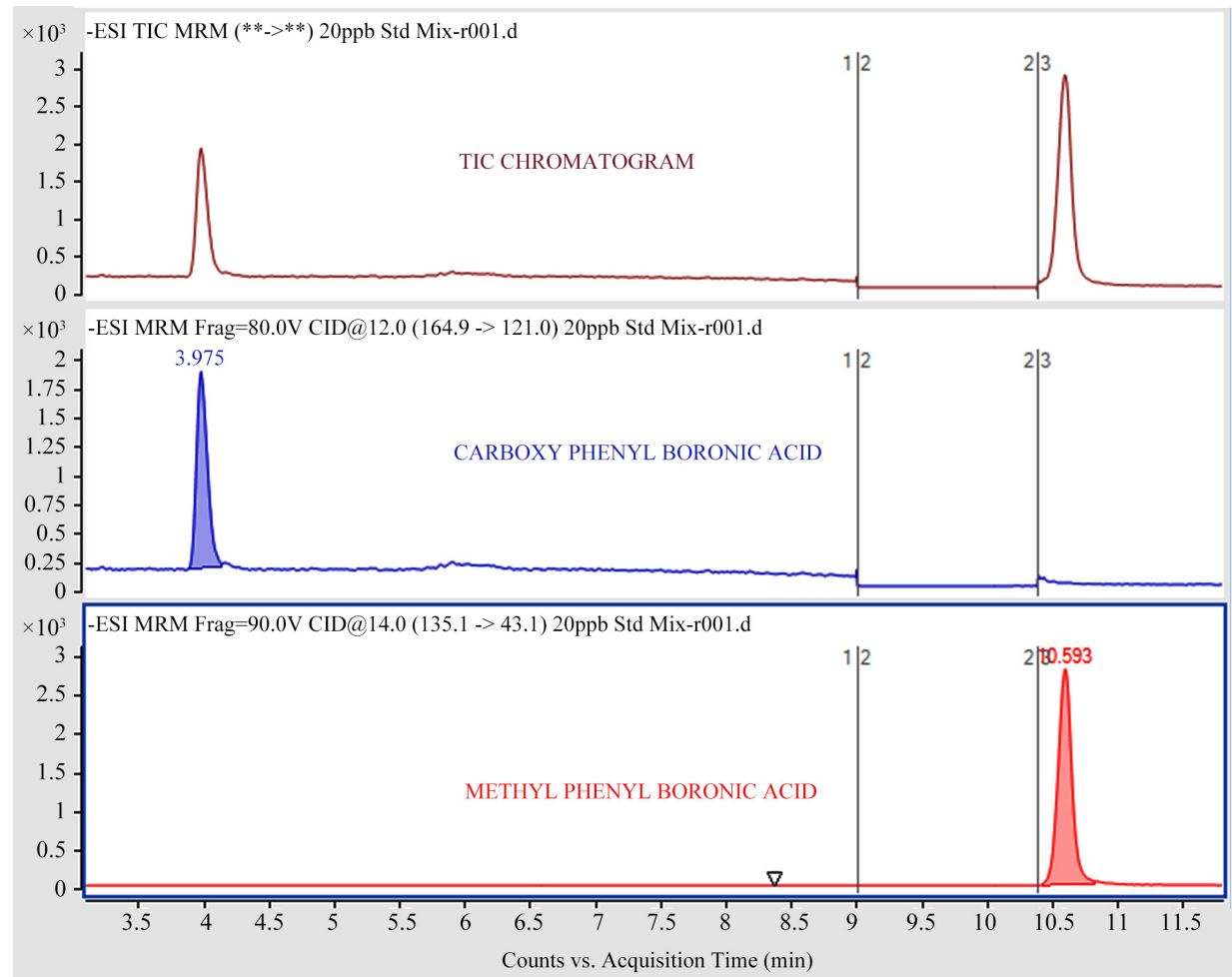

Figure $2.20 \mathrm{ng} / \mathrm{ml}$ (1.0 ppm wrt test) standard chromatogram for carboxy phenyl and methyl phenyl boronic acid impurities.

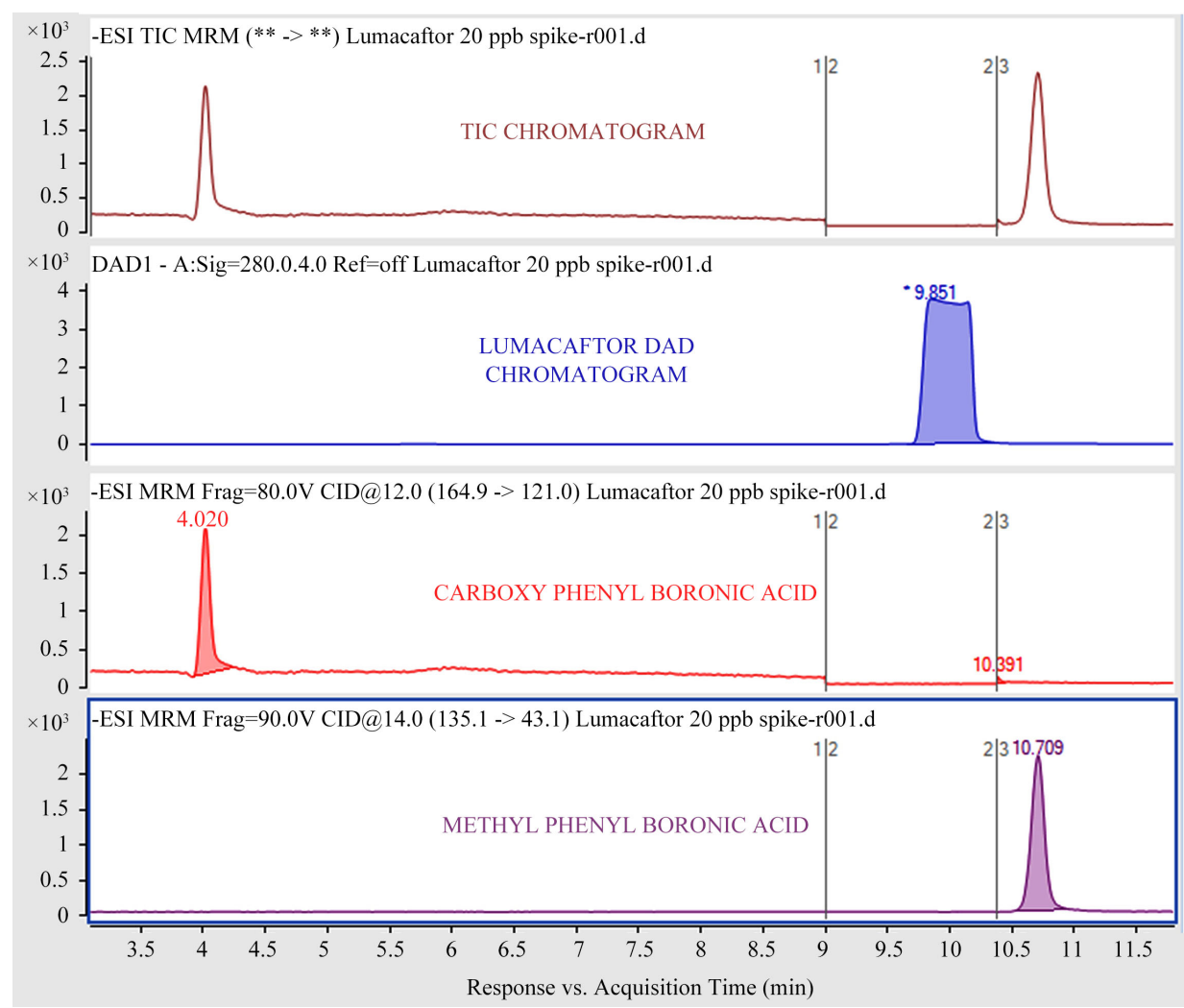

Figure 3. $20 \mathrm{ng} / \mathrm{ml}$ (1.0 ppm wrt test) spike chromatogram for carboxy phenyl and methyl phenyl boronic acid impurities. 


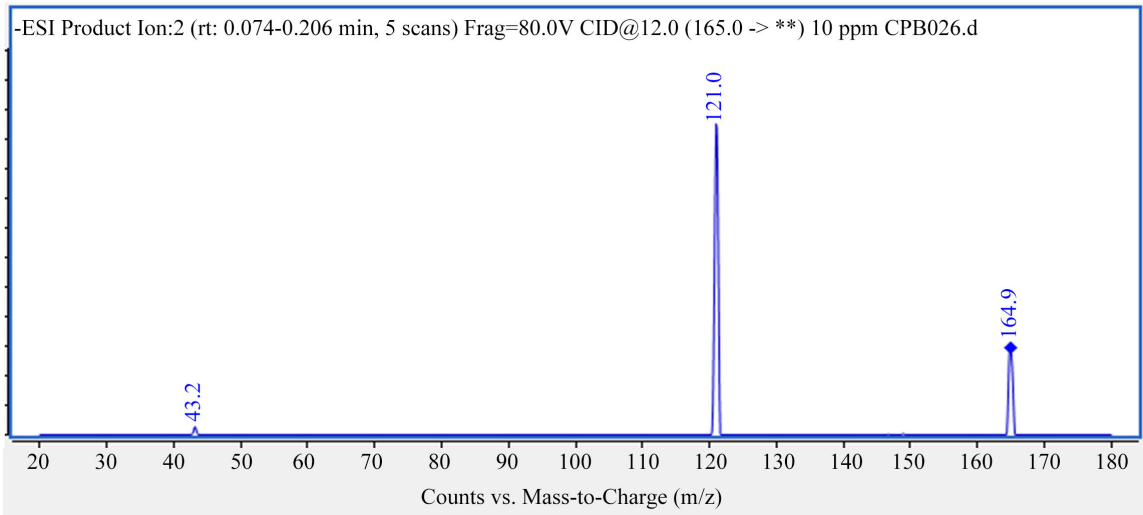

Figure 4. MSMS spectra of carboxy phenyl boronic acid.

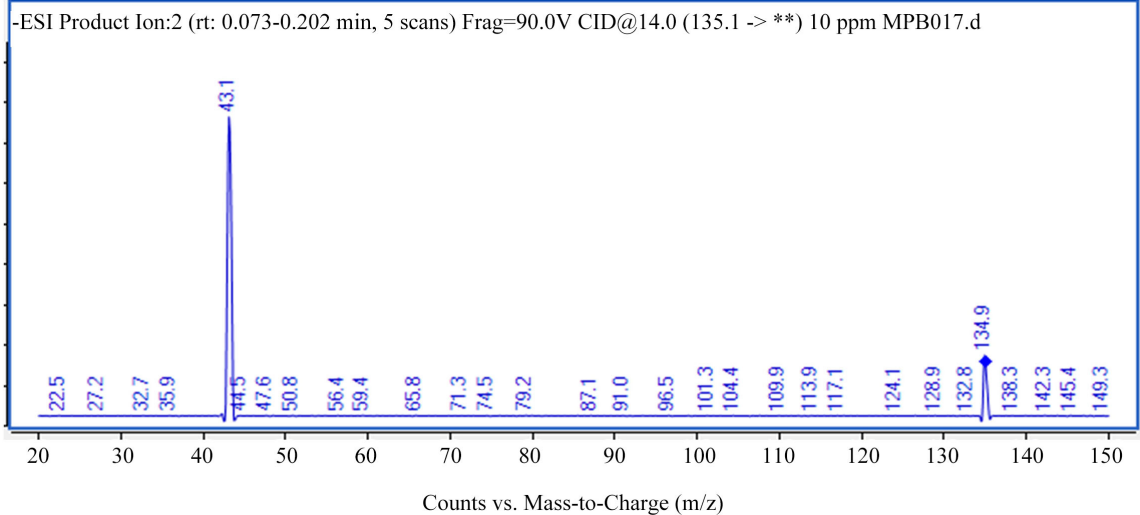

Figure 5. MSMS spectra of methyl phenyl boronic acid.

Table 1. Optimized MSMS parameters for Carboy phenyl and Methyl phenyl boronic acid impurities in ESI negative mode.

\begin{tabular}{cccccc}
\hline S. No & $\begin{array}{c}\text { Name of the } \\
\text { Impurity }\end{array}$ & $\begin{array}{c}\text { Precursor } \\
\text { ion }(\mathrm{m} / \mathbf{z})\end{array}$ & $\begin{array}{c}\text { Product ion } \\
(\mathrm{m} / \mathbf{z})\end{array}$ & $\begin{array}{c}\text { Fragmentor } \\
\text { voltage }(\mathrm{V})\end{array}$ & $\begin{array}{c}\text { Collison } \\
\text { energy }(\mathrm{V})\end{array}$ \\
\hline 1 & $\begin{array}{c}\text { Carboxy phenyl } \\
\text { boronic acid }\end{array}$ & 164.9 & 121.0 & 80 & 12 \\
2 & $\begin{array}{c}\text { Methyl phenyl } \\
\text { boronic acid }\end{array}$ & 134.9 & 43.1 & 90 & 14 \\
\hline
\end{tabular}

\section{Method Validation}

As per ICH recommended guidelines, the developed method was successfully validated and established all the critical parameters required to demonstrate the method efficiency.

\subsection{Specificity}

Lumacaftor with boronic acid impurities mix solution was prepared at required specification level in the diluent and then subjected to LCMSMS analysis. The results obtained shown that there was no interference of Lumacaftor API with carboxy phenyl and methyl phenyl boronic acid impurities. The chromatogram acquired was presented in Figure 2. 


\subsection{Linearity}

Method linearity was established from $1 \mathrm{ng} / \mathrm{ml}$ to $100 \mathrm{ng} / \mathrm{ml}(0.05-5 \mathrm{ppm})$ for both the boronic acid impurities. The regression coefficient, slope, and intercept values were derived using least squares linear regression analysis of average peak areas versus concentration of impurities. Good correlation between peak areas and concentrations of impurities observed as can be seen in Table 2 and linearity figures captured in Figure 6 \& Figure 7.

\subsection{LOD and LOQ}

The LOQ and LOD values for both the boronic acid impurities were determined based on $\mathrm{S} / \mathrm{N}$ ratios of 10.0 and 3.0 respectively, by injecting known standard concentrations and the results are captured in Table $2 . \mathrm{S} / \mathrm{N}$ ratio values are derived using peak to peak algorithm for both the boronic acid impurities. Recovery and reproducibility were also evaluated at LOQ level using triplicate injections. Reproducibility data at LOQ concentration for Carboxy phenyl and Methyl phenyl boronic acids also captured in Table 3.

Table 2. Linearity ranges, Correlation Coefficients, Signal to Noise ratios of LOQs and LODs for Carboxy phenyl and Methyl phenyl boronic acid impurities.

\begin{tabular}{|c|c|c|c|c|c|}
\hline \multirow[b]{2}{*}{ S. No } & \multirow[b]{2}{*}{$\begin{array}{l}\text { Name of the } \\
\text { Impurity }\end{array}$} & \multirow[b]{2}{*}{$\begin{array}{c}\text { Linearity } \\
\text { Range (ppm) }\end{array}$} & \multirow[b]{2}{*}{$\begin{array}{c}\text { Correlation } \\
\text { coefficient }\left(\mathrm{R}^{2}\right)\end{array}$} & \multicolumn{2}{|c|}{$\begin{array}{c}\text { S/N ratio } \\
\text { (Peak to Peak basis) }\end{array}$} \\
\hline & & & & $\begin{array}{c}\text { LOQ } \\
(0.25 \mathrm{ppm})\end{array}$ & $\begin{array}{c}\text { LOD } \\
(0.05 \mathrm{ppm})\end{array}$ \\
\hline 1 & $\begin{array}{l}\text { Carboxy phenyl } \\
\text { boronic acid }\end{array}$ & $0.05-5$ & 0.9974 & 26.8 & 7.4 \\
\hline 2 & $\begin{array}{l}\text { Methyl phenyl } \\
\text { boronic acid }\end{array}$ & $0.05-5$ & 0.9915 & 150.6 & 43.4 \\
\hline
\end{tabular}

Table 3. Repeatability data for carboxy phenyl and methyl phenyl boronic acid impurities at $5 \mathrm{ng} / \mathrm{ml}(0.25 \mathrm{ppm})(\mathrm{LOQ})$.

\begin{tabular}{cccc}
\hline S.NO & $\begin{array}{c}\text { Carboxy phenyl } \\
\text { boronic acid }\end{array}$ & $\begin{array}{c}\text { Methyl phenyl } \\
\text { boronic acid }\end{array}$ \\
\hline 1 & 3249 & 4435 \\
Initial Replicates & $\mathbf{3}$ & 2617 & 4118 \\
& 4 & 2669 & 4299 \\
& $\mathbf{5}$ & 2845 & 4605 \\
$\mathbf{6}$ & 2751 & 4577 \\
& Average & 2695 & 4380 \\
\hline STD DEV & 2804.3 & 4402.3 \\
& \%RSD & 8.2 & 181.5 \\
\hline
\end{tabular}




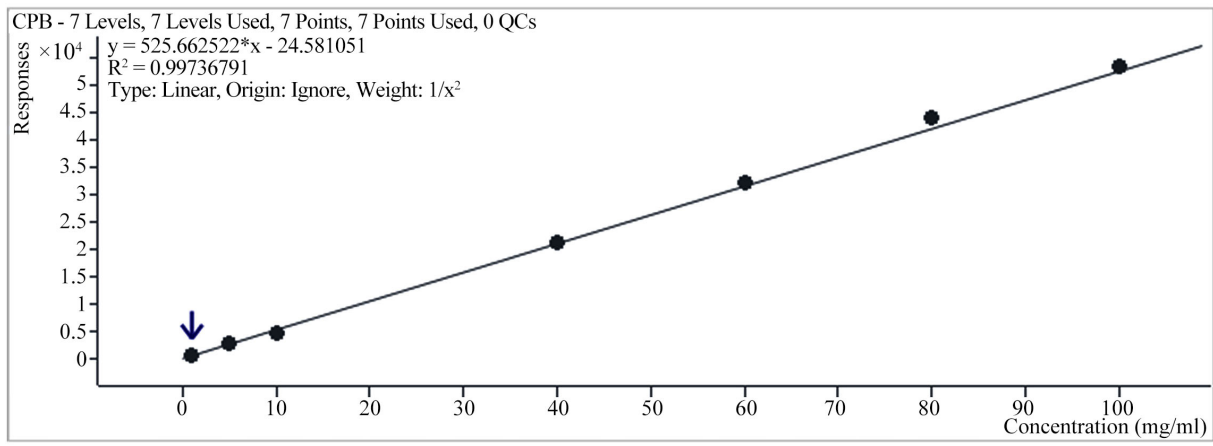

Figure 6. Linearity generated from $1 \mathrm{ng} / \mathrm{ml}$ to $100 \mathrm{ng} / \mathrm{ml}(0.05-5 \mathrm{ppm})$ for carboxy phenyl boronic acid.

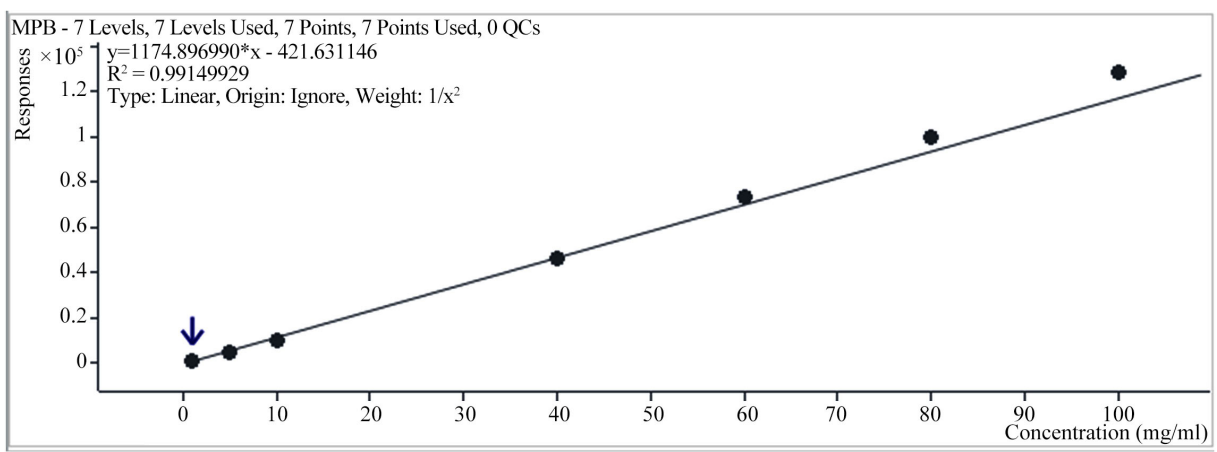

Figure 7. Linearity generated from $1 \mathrm{ng} / \mathrm{ml}$ to $100 \mathrm{ng} / \mathrm{ml}(0.05-5 \mathrm{ppm})$ for methyl phenyl boronic acid.

\subsection{Accuracy and Recovery}

Deviation from linearity standard concentrations was referred to as accuracy and was evaluated by injecting impurity mixture from LOQ which is $25 \%$ of specification limit and on 5 times the specification limit. The acceptance criteria for accuracy is between $80 \%-120 \%$ for all the linearity standards except LOQ which could be $70 \%-130 \%$ for such a low concentration range. Accuracy values observed at all levels for both the boronic acid impurities were within $15 \%$ which are well within the required acceptance criteria. Recovery was evaluated by standard addition method in triplicate at two concentrations at $0.25 \mathrm{ppm}$ and 1.0 ppm levels in Lumacaftor API. The acceptance criteria for recovery is $80 \%$ $120 \%$. The percentage recoveries for both the boronic acid impurities presented in Table 4.

\subsection{Robustness}

Method robustness was evaluated changing different conditions of the method including the flow rate and composition of the mobile phase and column oven temperatures. The optimized flow rate of the mobile phase was $0.25 \mathrm{~mL} / \mathrm{min}$ and the same was altered from 0.225 to $0.275 \mathrm{ml} / \mathrm{min}$. The effect of column oven temperature on resolution was studied at $35^{\circ} \mathrm{C}$ and $45^{\circ} \mathrm{C}$ (altered by $5.0^{\circ} \mathrm{C}$ ). There was no impact on chromatographic performance of both the boronic acid impurities due to the mentioned changes proving the method robustness based 
on the obtained results.

\subsection{Repeatability and Solution Stability}

Repeatability of the developed method was evaluated by injecting six replicate injections at $20 \mathrm{ng} / \mathrm{ml}(1.0 \mathrm{ppm})$ mixture of boronic acid impurities and observed the \%RSD after including multiple bracketing standards. The acceptance criteria for cumulative \%RSD is less than $15 \%$. The RSD values achieved for both the boronic acid impurities are less than $6.1 \%$ which are well within the acceptance criteria which are presented in Table 5 . Repeatability overlaid chromatogram for both the boronic acid impurities captured in Figure 8. The solution stability study of lumacaftor and boronic acid mixture was evaluated by placing spiked and un spiked sample solutions at $25^{\circ} \mathrm{C}$ for $24 \mathrm{~h}$ and measured against freshly prepared standard solutions and there were no significant changes observed for any of the impurities. Therefore, we confirmed the stability of impurities in sample solution for at least 24 hours.
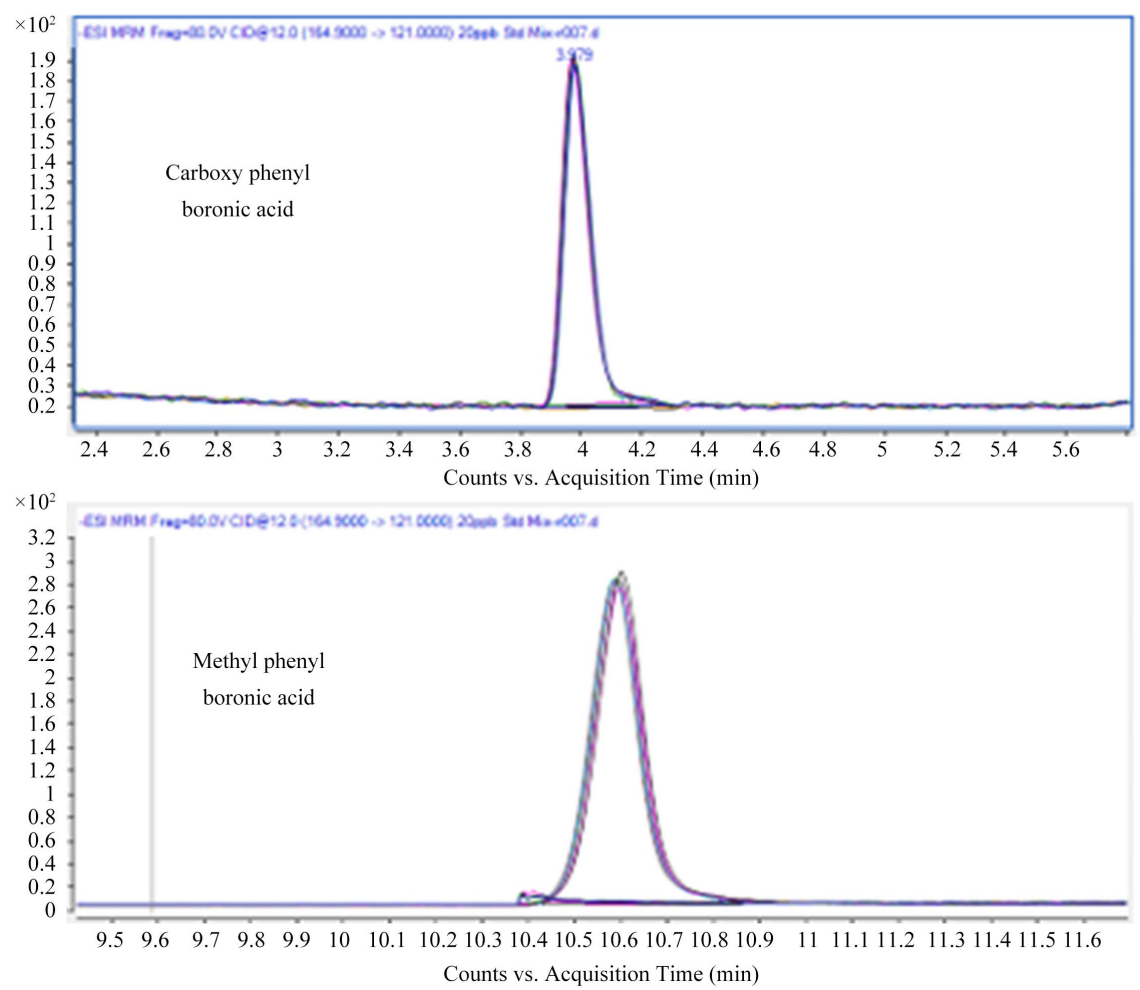

Figure 8. Repeatability overlay of seven injections including bracketing standard for carboxy phenyl and methyl phenyl boronic acid impurities in lumacaftor.

Table 4. Recoveries of carboxy phenyl and methyl phenyl boronic acid impurities at 1.0 ppm and $0.25 \mathrm{ppm}$ (LOQ).

\begin{tabular}{cccc}
\hline S. No & Name of the Impurity & Recovery at $\mathbf{1 . 0}$ ppm & Recovery at $\mathbf{0 . 2 5} \mathbf{p p m}$ \\
\hline 1 & Carboxy phenyl boronic acid & 92.8 & 90.6 \\
2 & Methyl phenyl boronic acid & 88.2 & 92.0 \\
\hline
\end{tabular}


Table 5. Repeatability data for carboxy phenyl and methyl phenyl boronic acid impurities at $20 \mathrm{ng} / \mathrm{ml}(1.0 \mathrm{ppm})$ including bracketing standard.

\begin{tabular}{cccc}
\hline S.NO & $\begin{array}{c}\text { Carboxy phenyl } \\
\text { boronic acid }\end{array}$ & $\begin{array}{c}\text { Methyl phenyl } \\
\text { boronic acid }\end{array}$ \\
\hline 1 & 10,720 & 21,137 \\
2 & 11,323 & 20,763 \\
Initial Replicates & 3 & 11,046 & 20,749 \\
& 4 & 11,100 & 20,932 \\
& 5 & 9912 & 21,248 \\
& 6 & 10,471 & 20,494 \\
Bracketing standard & 7 & 9601 & 21,683 \\
& Average & $10,596.1$ & $21,000.9$ \\
& \%RD DEV & 642.1 & 393.0 \\
\hline
\end{tabular}

\section{Conclusion}

In summary, the work presented here is novel in terms of simultaneous determination of mutagenic underivatized boronic acid impurities in lumacaftor active pharmaceutical ingredient by single method using LC-MS/MS and there is no literature available for the quantification of underivatized boronic acids in drug substances. We could also perform all the critical parameters to prove the method performance and complete method validation as per ICH recommendations. The LOD and LOQ values determined for both the boronic acid impurities are very low showing the high sensitivity performance of the method. The method is completely validated and presents good reproducibility, linearity, recovery, and robustness. The method developed and presented here could be very useful for the determination of boronic acid impurities in lumacaftor drug substance during routine manufacturing process increasing the throughput and also could help in establishing the safety of the active pharmaceutical ingredient.

\section{Conflicts of Interest}

To the best of our knowledge, this is the first method published for simultaneous determination of underivatized Carboxy phenyl and Methyl phenylboronic acids in Lumacaftor drug substance and hold no conflicts to declare.

\section{References}

[1] Miyuara, N. and Suzuki, A. (1995) Palladium-Catalyzed Cross-Coupling Reactions of Organoboron Compounds. Chemical Reviews, 95, 2457-2483. https://doi.org/10.1021/cr00039a007

[2] Hansen, M.M., Jolly, R.A. and Lynder, R.J. (2015) Boronic Acids and Derivatives-Probing the Structure-Activity Relationships for Mutagenicity. Organic Process Research \& Developments, 19, 1507-1516. 
https://doi.org/10.1021/acs.oprd.5b00150

[3] Ames, B.N., Lee, F.D. and Durston, W.E. (1973) An Improved Bacterial Test System for the Detection and Classification of Mutagens and Carcinogens. Proceedings of the National Academy of Sciences of the United States of America, 70, 782-786. https://doi.org/10.1073/pnas.70.3.782

[4] ICH M7 Assessment and Control of DNA Reactive (Mutagenic) Impurities in Pharmaceuticals to Limit Potential Carcinogenic Risk. https://database.ich.org/sites/default/files/M7_R1_Guideline.pdf

[5] Cholon, D.M., Esther Jr., C.R. and Gentzsch, M. (2016) Efficacy of Lumacaftor-Ivacaftor for the Treatment of Cystic Fibrosis Patients Homozygous for the F508del-CFTR Mutation. Expert Review of Precision Medicine and Drug Development, 1, 235-243. https://doi.org/10.1080/23808993.2016.1175299

[6] Cheng, P.C., Alexiou, S. and Rubenstein, R.C. (2019) Safety and Efficacy of Lumacaftor in Combination with Ivacaftor in Younger Patients with Cystic Fibrosis. EXpert Review of Respiratory Medicine, 13, 417-423.

https://doi.org/10.1080/17476348.2019.1602040

[7] Chlivers, M.A., Davies, J.C., Milla, C., Tian, S., Han, Z. and Cornell, A.G. (2021) Long-Term Safety and Efficacy of Lumacaftor-Ivacaftor Therapy in Children Aged 6-11 Years with Cystic Fibrosis Homozygous for the F508del-CFTR Mutation: A Phase 3, Open Label, Extension Study. The Lancet Respiratory Medicine. https://doi.org/10.1016/S2213-2600(20)30517-8

[8] Bulloch, M.N., Hanna, C. and Giovane, R. (2017) Lumacaftor/Ivacaftor, a Novel Agent for the Treatment of Cystic Fibrosis Patients Who Are Homozygous for the F508del-CFTR Mutation. Expert Review of Clinical Pharmacology, 10, 1055-1072. https://doi.org/10.1080/17512433.2017.1378094

[9] Pandiyan, P.J., Appadurai, R. and Ramesh, S. (2013) A High Throughput Analysis of Boronic Acids Using Ultra High-Performance Liquid Chromatography-Electrospray Ionization Mass Spectrometry. Analytical Methods, 5, 3386-3394. https://doi.org/10.1039/c3ay40542g

[10] Mullangi, S., Ravindhranath, K. and Panchakarla, R.K. (2021) LC-MS/MS Method for the Quantification of Potential Genotoxic Impurity 4-Phenoxyphenyl-Boronic Acid in Ibrutinib. Journal of the Iranian Chemical Society. https://doi.org/10.1007/s13738-020-02118-3

[11] Baldwin, A.F., North, R. and Eisenbeis, S. (2019) Trace Level Quantification of Derivatized Boronic Acids by LC-MS/MS. Organic Process Research \& Development, 23, 88-92. https://doi.org/10.1021/acs.oprd.8b00377

[12] Schneider, E.K., Reyes-Ortega, F., Li, J. and Velkov, T. (2017) Optimized LC-MS/MS Method for the High Throughput Analysis of Ivacaftor, Its Major Metabolites, and Lumacaftor in Biological Fluids of Cystic Fibrosis Patients. Journal of Visualized Experiments, 128, e56084. https://doi.org/10.3791/56084

[13] Schneider, E.K., Reyes-Ortega, F., Wilson, J.W., et al. (2016) Development of HPLC and LC-MS/MS Method for the Analysis of Ivacaftor, Its Major Metabolites, and Lumacaftor in Plasma an Sputum of Cystic Fibrosis Patients Treated with ORKAMBI or KALYDECO. Journal of Chromatography B, 1038, 57-62. https://doi.org/10.1016/j.jchromb.2016.10.026

[14] Dastagiri, J., Sivagami, B., Chandrasekar, R., et al. (2019) Stability Indicating RP-HPLC Method for Simultaneous Estimation of Lumacaftor and Ivacaftor in Bulk and Pharmaceutical Dosage Form. Journal of Pharmaceutical Sciences \& Research, 11, 2898-2904. 
[15] Gorantla, N., Dodlapati, J. and Jadi, S. (2019) A New Validated RP-HPLC Method for Simultaneous Estimation of Lumacaftor and Ivacaftor in Pharmaceutical Dosage Form. International Journal of Pharmaceutical Sciences Review and Research, 56, 30-37.

[16] ICHQ2(R1) Validation of Analytical Procedures: Text and Methodology. https://database.ich.org/sites/default/files/Q2\%28R1\%29\%20Guideline.pdf 